Research article

\title{
Impact of dust accumulation on three roadside plants and their adaptive responses at National Highway 37, Assam, India
}

\author{
Bitopan Sarma $^{1,2}$, Sanjay Kumar Chanda ${ }^{2}$ and Mantu Bhuyan ${ }^{2 *}$ \\ ${ }^{1}$ Academy of Scientific and Innovative Research, CSIR-North East Institute of Science and Technology, \\ Jorhat, Assam, India \\ ${ }^{2}$ Biological Science and Technology Division, CSIR-North East Institute of Science and Technology, \\ Jorhat, Assam, India \\ *Corresponding Author: mantubhuyan@gmail.com \\ [Accepted: 13 April 2017]
}

\begin{abstract}
Roadside plants are consistently exposed to dust. Deposition of dust on roadside plant and its impact on leaf epidermal traits as well as leaf pigment concentration, the percentage of carbon and nitrogen has been studied of three roadside plants i.e. Cassia alata, C. tora and $C$. sofera at National Highway - 37, Assam. Significant variation in terms of dust deposition with species specific result observed during the study. Declination of leaf pigment concentration, leaf area and nitrogen percentage along with increased leaf thickness indicate the dust pollution impact. Above findings may be helpful to find out some representative species for developing some model to cope with automobile generated dust pollution in future.
\end{abstract}

Keywords: Dust pollution - Roadside plant - Chlorophyll - Leaf epidermal traits - Cassia spp.

[Cite as: Sarma B, Chanda SK \& Bhuyan M (2017) Impact of dust accumulation on three roadside plants and their adaptive responses at National Highway 37, Assam, India. Tropical Plant Research 4(1): 161-167]

\section{INTRODUCTION}

Dust is an important abiotic factor and has a key influence upon the organism. Sever pressure of dust may be responsible for altering bio-chemical as well as morphological setup of an organism which further initiated adaptive evolution to cope with the changing environment. Based on the source of generation as well as the structure of road, the role of dust may be variable (Farmer 1993, Anthony 2001). In an urban area, road dust contains a mainly huge amount of different metals as well as a small amount of clay and minerals too (Beckett et al. 2000). Vehicles are the prime source of dust generation for roadside plants. Poor road infrastructure, the frequency of running vehicles in terms wheel determine the rate of dust generation. Therefore, adaptive evolution of roadside plant species is more visible in poor road infrastructure with more running vehicles. The response of the plant to dust accumulation may vary according to different species, as dust deposition fluctuates with plant species due to leaf orientation, leaf surface geometry, phyllotaxy, epidermal and cuticular features, leaf pubescence, height and canopy of roadside plants (Davison \& Blakemore 1976, Chaphekar et al. 1980, Farmer 1993, Chaturvedi et al. 2013) With the accumulation of dust, the roadside plant may exhibit adaptive response by changing morphological and physiological attributes.

A number of registered motor vehicles in India have reached from 0.3 million to 159.5 million from 1951 to 2012 (Report: Road Transport Year Book 2011-12, Government of India, Ministry of Road Transport and Highways Transport Research Wing, www.morth.nic.in). In Assam, vehicles are increased from 53, 4885 in 2000-01 to 1,98,4880 in 2013-14 indicating 73.05\% boost of the growth of motor vehicle in the state. But the roads are limited and poor in condition (Source: Office of the Commissioner of Transport, Assam and Directorate of Economics and Statistics, Assam). National Highway - 37 (NH-37) is the backbone of road transport in Assam and the road starts from Panchatantra of Goalpara district of Assam to Roing of Arunachal Pradesh with a length of $740 \mathrm{~km}$ and considered one of the busiest road connecting all the major cities of the south of the Brahmaputra river.

In the present study, we emphasised the impact of dust deposition in terms of epidermal traits of leaf, chlorophyll contents, carbon and nitrogen percentage upon roadside plant and their adaptive responses to cope 
with the vehicular dust deposition. Three common shrub species of the genus Cassia i.e. Cassia alata L., C. tora L. and C. sofera L. selected to study the impact of vehicular dust and their adaptive response.

\section{MATERIALS AND METHODS}

CSIR-North East Institute of Science and Technology (CSIR-NEIST) is situated towards south to NH-37. A site on the NH-37 in front of CSIR-NEIST was selected to study vehicular load/ hour on NH-37 and the road was monitored continuously in a different time interval of the day up to one month. Total numbers of vehicles including two, three and >three wheelers (four wheelers and above) vehicles crossed from both sides has been counted and the average value was calculated per hour.

Based on the frequency of occurrence on the roadside of NH-37, 3 months old three plant species of the genus Cassia i.e. Cassia alata L. Cassia tora L. and Cassia sofera L. have been selected to study the accumulation of dust and its impact on the plants. Leaves were collected randomly of from plants with equal height from each species growing along with the roadside of NH-37, after the seasonal rainfall of Assam in April, 2015. Leaves from the three roadside plant species were collected in zipper pouches separately, in triplicate and brought to the laboratory for estimation of dust deposition. Each leaf was washed with distilled water using a spray bottle and suspended dust along with the water was collected carefully on pre-weighed Whatman's filter paper (pore size $110 \mathrm{~mm}$ ). The filter papers were dried in an oven at $40-50{ }^{\circ} \mathrm{C}$ for 2 hours to remove the water and weighed later to calculate the dust deposition in $\mathrm{mg} / \mathrm{cm}^{2}$ of the leaf. Washed leaves were blotted dry and then traced on graph paper to measure the total leaf area in $\mathrm{mm}^{2}$ (Chaphekar et al. 1980, Vora \& Bhatnagar 1986). Prominent secondary veins, as well as midrib of the leaf was avoided to reduce sample variation during measuring leaf area. Number of stomata and epidermal cell present per $\mu \mathrm{m}$ of each of the collected leaf from all the three plant species were calculated to estimate the Stomatal Index of the leaves. Mature leaf was fixed in FAA solution (acetic acid: alcohol: formalin: water $=2: 5: 1: 12$ ) for 24 hours followed by washing the leaf in $70 \%$ ethanol and then each leaf samples were cut out into circular form for easy peeling. Cut leaves were boiled in 5\% aqueous solution of $\mathrm{KOH}$ for 5-10 minute and adaxial and abaxial surface was peeled and peeled section was stained with $1 \%$ safranin followed by temporary mounting in glycerin to observe the number of stomata as well as epidermal cell under the microscope (Leica DM-3000 LED, Made in Germany) (Satao et al. 1993). At least three microscopic observations at 20X were considered for counting. Stomatal index (I) was calculated by the following formula (Meidner \& Mansfield 1968),

$$
I=\frac{S}{(S+E)}
$$

Where, $(\mathrm{S})=$ Numbers of stomata, $(\mathrm{E})=$ Numbers of epidermal cells present in a unit area ${ }^{2}$

Leaf pigments i.e. chlorophyll a, b and total chlorophyll concentration was counted with the method described by (Arnon 1949) and the pigment concentration was expressed in $\mathrm{mg} \cdot \mathrm{g}^{-1}$ tissue. Carbon and nitrogen percentage in leaf were determined by the Perkin Elemental CHN analyser. Microsoft Excel 2010 version is used for analysis. Data were entered and arranged accordingly to calculate Standard Deviation (SD) and Standard Error (SE) from different replicated samples (Federrer 1947). One way ANOVA is using with Sigma Plot statistical software v13 (Jandel Scientific, San Rafael, CA). All groups were compared using the StudentNewman-Keuls post hoc analysis method. The $p$ value less than 0.05 was considered to be statistically significant.

\section{RESULTS}

National Highway - 37 is one the one of the busiest roads of communication, connecting maximum numbers of cities of Assam. The road bears the vehicular load of an average of 580 numbers of vehicles i.e. two, three and $>$ three wheelers (four wheelers and above) per hour. More than three wheelers vehicles were more frequent followed by two and three wheeler vehicles on the NH-37 (Fig. 1A). Irrespective of plant species, deposition of dust on leaf of roadside plant was found to increase significantly with time. Amount of dust deposited in the leaf of $C$. tora was maximum followed by leaf of C. sofera and C. alata during $1^{\text {st }}$ and $2^{\text {nd }}$ week (Fig. 1B). However, during $3^{\text {rd }}$ and $4^{\text {th }}$ week dust deposition was found higher in C. sofera followed by C. tora and C. alata.

Leaf chlorophyll is an important index to measure the impact of dust on the roadside plant species. Leaf pigment concentration i.e. chlorophyll was found to decreased considerably in the roadside plant species compare to control. It is evident from table 1 that roadside plant produces less chlorophyll a, chlorophyll b and total 


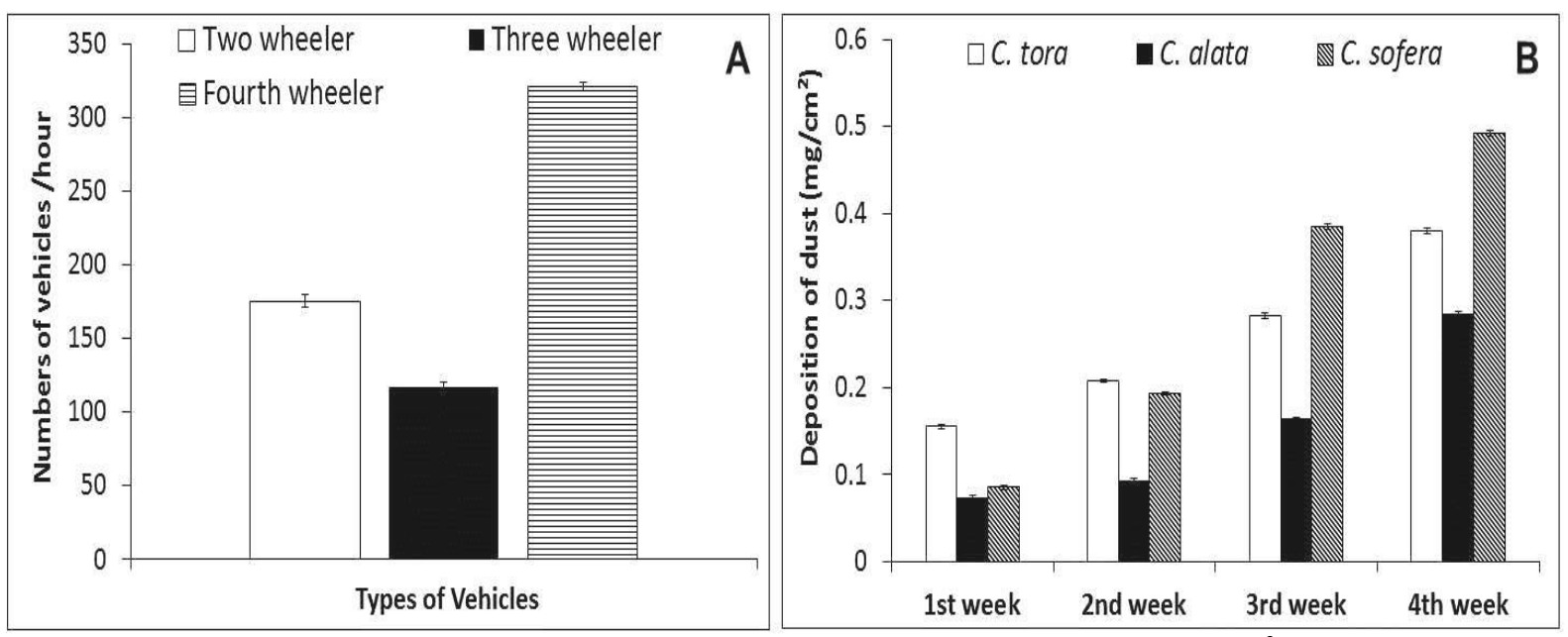

Figure 1. A, Average numbers of different vehicles per hour at NH-37; B, Dust deposition $\left(\mathrm{mg} / \mathrm{cm}^{2}\right)$ on the leaf of Cassia tora, C. alata and C. sofera.

Table 1. Chlorophyll (chlorophyll a, b and total) contents of leaves of three different Cassia species in different sites.

\begin{tabular}{|c|c|c|c|c|}
\hline Species & Site & Chlorophyll a (mg.g $\left.{ }^{-1}\right)$ & Chlorophyll b (mg.g $\left.{ }^{-1}\right)$ & Total \\
\hline \multirow{3}{*}{ 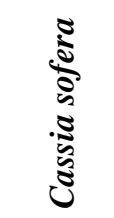 } & Control & $1.87^{\mathrm{a}} \pm 0.026^{*}$ & $0.89^{\mathrm{A}} \pm 0.012^{*}$ & $2.47^{\mathrm{aa}} \pm 0.023^{*}$ \\
\hline & NH-37 & $1.57^{\mathrm{b}} \pm 0.012$ & $0.87^{\mathrm{A}} \pm 0.022$ & $2.21^{\mathrm{bb}} \pm 0.025$ \\
\hline & Reduction (\%) & 16.04 & 2.24 & 10.52 \\
\hline \multirow{3}{*}{ 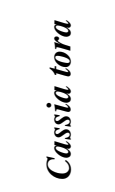 } & Control & $1.88^{\mathrm{c}} \pm 0.041$ & $1.05^{\mathrm{B}} \pm 0.032$ & $2.62^{\mathrm{cc}} \pm 0.030$ \\
\hline & NH-37 & $1.43^{\mathrm{d}} \pm 0.020$ & $0.86^{\mathrm{C}} \pm 0.008$ & $2.12^{\mathrm{dd}} \pm 0.032$ \\
\hline & Reduction (\%) & 23.93 & 18.09 & 19.08 \\
\hline \multirow{3}{*}{ 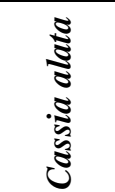 } & Control & $1.94^{\mathrm{e}} \pm 0.027$ & $0.92^{\mathrm{D}} \pm 0.010$ & $2.91^{\mathrm{ee}} \pm 0.011$ \\
\hline & NH-37 & $1.55^{\mathrm{f}} \pm 0.031$ & $0.73^{\mathrm{E}} \pm 0.009$ & $2.31^{\mathrm{ff}} \pm 0.013$ \\
\hline & Reduction (\%) & 20.1 & 20.62 & 20.61 \\
\hline
\end{tabular}

Note: $*$ Values are mean \pm SE $(n=10)$. Each rows having different letters are significant at $\mathrm{p}<0.05$ level.

chlorophyll than the control. The percentage of reduction of chlorophyll content was found highest in $C$. alata plant species. Reduction of Specific Leaf Area (SLA), Stomatal index (adaxial and abaxial) and Leaf Dry Matter Content (LDMC) were observed in all the three plant species growing along the roadside of NH-37 compare to control (vehicle free zone) (Fig. 2A-D). All those parameters were different among all the three species even in control. However irrespective of plant species, the above mentioned leaf parameters were recorded lower in the leaf of roadside plant species. Maximum percentage of reduction of SLA was observed in the leaves of $C$. sofera (Fig. 2A), but highest percentage reduction of the stomatal index for both abaxial and adaxial surface of the leaves was recorded in $C$. tora plant. Similarly, $C$. tora also exhibited maximum percent reduction of LDMC (Fig. 2B-D).

On the other hand, leaf thickness of each plant species from roadside was found to increase in compare to control (Fig. 2E). Leaf thickness of $C$. tora was significantly higher than rest of the two plant species, but highest percentage increase was recorded in $C$. sofera. Nitrogen content of plant is a limiting resource for plant growth, reproduction and defence. Roadside plant exhibited less nitrogen with highest reduction in $C$. sofera followed by $C$. alata and $C$. tora (Fig. 3A). However, dust exposure roadside plant presenting higher accumulation of carbon content in all studied plant and highest percentage of increase was recorded in $C$. sofera plant followed by $C$. alata and C. tora (Fig. 3B). It is evident from (Fig. 3A-B) that highest reduction of nitrogen of the plant is associated with the highest increase of carbon (C. sofera) and lowest nitrogen of the plant associated with lowest carbon (C. tora). 

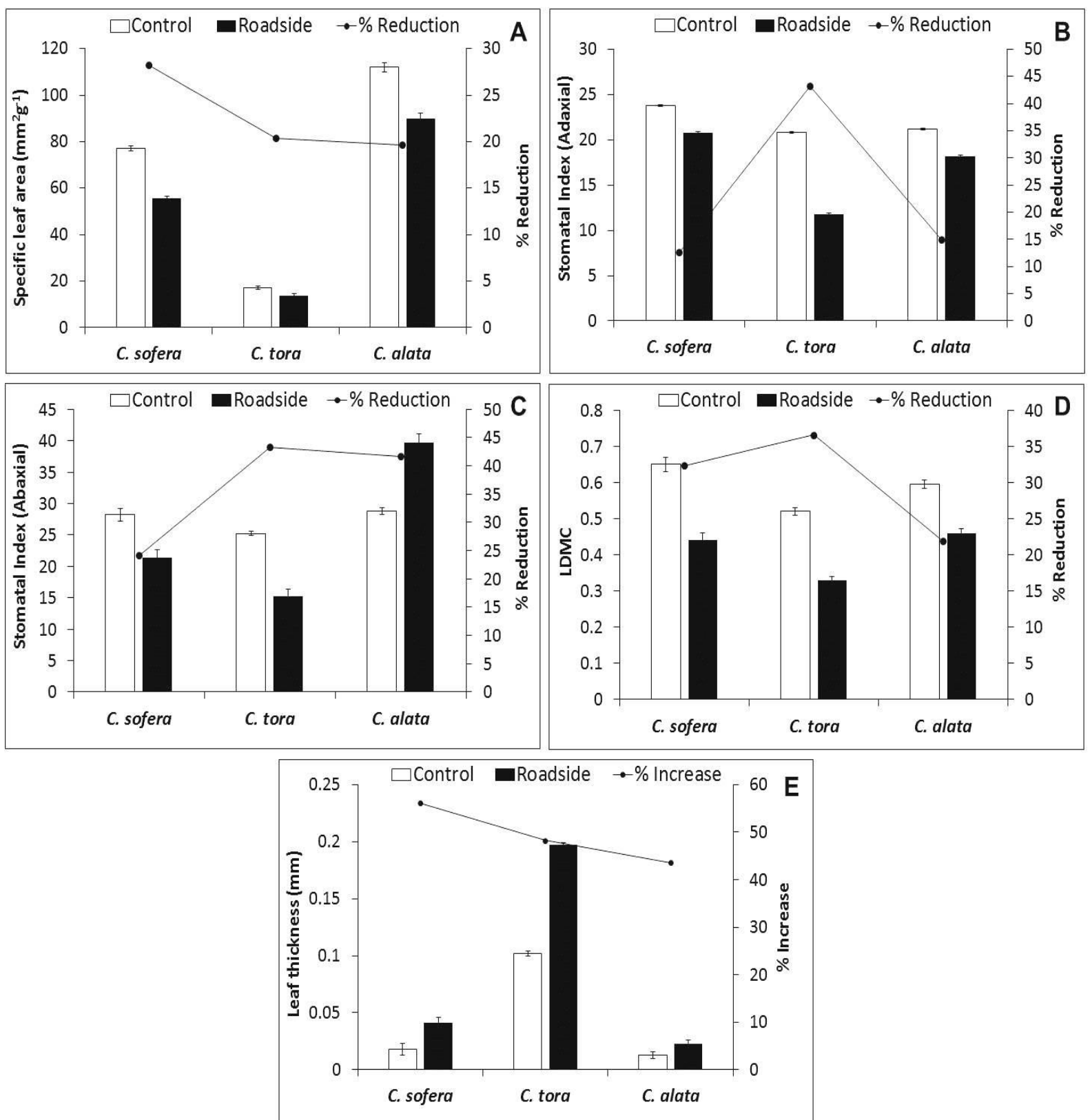

Figure 2. A, Specific leaf area (SLA); B, Stomatal index (Adaxial); C, Stomatal index (Abaxial); D, Leaf dry matter content (LDMC); E, Leaf thickness of leaf of the control and roadside plant of Cassia tora, C. alata and C. sofera.

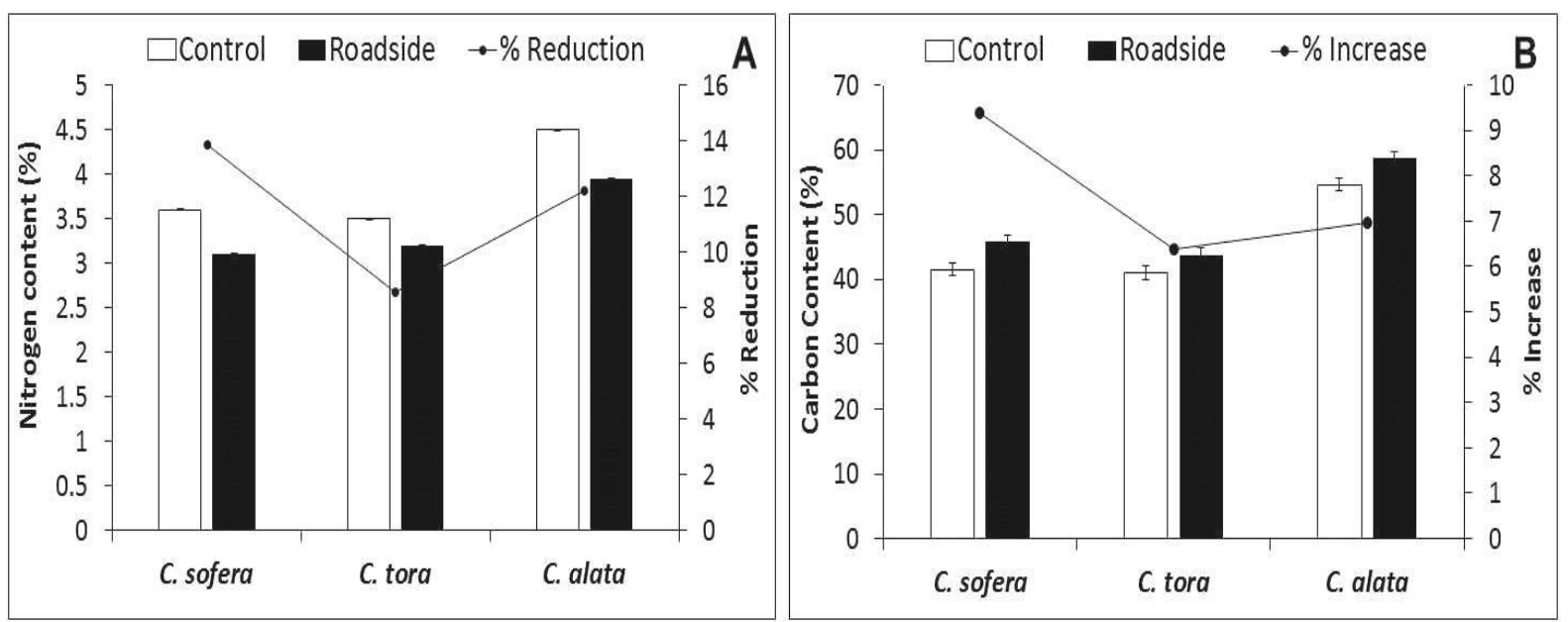

Figure 3. A, Nitrogen content (\%); B, Carbon content (\%) of the leaf of the control and roadside plant of Cassia tora, $C$. alata and C. sofera.

www.tropicalplantresearch.com 


\section{DISCUSSION}

Rolling vehicles put force to the road surface and pulverizes the roadbed materials in the form of dust; eject it in shearing force and turbulent vehicle force (Khan et al. 2015). The pulverization of roadbed materials will be more in the poor road with more vehicles. NH-37 in Assam is poor in quality and >three wheelers (four wheelers and above) are dominant on the road. In poor road, more numbers wheels can faster dust generation. Roadside plants i.e. Cassia sofera, C. tora and C. alata of NH-37 are consistently exposed to dust. The dust particles settled on the leaf surfaces every day, but deposition was not uniform in all the plant species. Settlement of dust particle on the leaf surface mainly depends on the phylotaxy of leaf, smoothness of the leaf surface, shape of leaf, petiole length as well as its position in the plant (Davison \& Blakemore 1976). On the basis of leaf structure and texture, local air movement influence to dislodge deposited dust from the leaf. However, during the study period, local air movement was found to be insignificant. Therefore, variation of dust deposition was observed in leaves of different plant species. Dust deposition was also found to increase with time. Dust generated from day to day traffic activity will be accumulated on the leaf up to a limit. Hence, irrespective of plant species, dust deposition was found to increase in different time intervals. It was also observed that during the first two weeks, dust deposition was found highest on the leaf of $C$. tora followed by $C$. sofera and $C$. alata. But after $2^{\text {nd }}$ week the pattern of dust deposition changed and highest accumulation was recorded in $C$. sofera then to $C$. tora and $C$. alata. Leaf structure and texture determine the limit of dust deposition. According to plant species, dust load per day may very i.e. initial rate of dust deposition may increase in some plant species and deposition rate decrease with time. Here the size of leaf and overall height of the plant species may also contribute. Leaf petiole and surface characteristics may be responsible for the higher rate of dust deposition in $C$. sofera during 3rd and 4th week. In addition to the leaf surface characteristics, the position of leaves on the plant and their orientation also crucial in terms of dust deposition.

Structural properties of the leaf are influenced by deposition of dust, which may lead to lower photosynthesis activity (Pourkhabbaz et al. 2010). All the studied roadside plant species showed reduction of chlorophyll contents (chlorophyll a, b and total chlorophyll) in compare to vehicle free site (control). Dust particles physically obstruct sunlight as well as block stomatal pore of leaf and thus dust deposition hampered photosynthetic activities of plant (Nicholson et al. 1989, Keller \& Lamprecht 1995, Pandey \& Kumar 1996, Hope et al. 1999, Manno et al. 2006). Shading effect of dust as well as alkaline condition caused by dissolution of dust particles in cell sap degrade leaf pigment concentration has been reported earlier (Prajapati \& Tripathi 2008a). Degradation of chlorophyll contents in the leaf is a common phenomenon from dust deposition on leaf (Prajapati \& Tripathi 2008b). A plenty of studies (Satao et al. 1993, Prusty et al. 2005, Gostin 2009) reviewed declination of chlorophyll concentration due to deposition of dust in a number of the annual non-leguminous crop.

SLA which is a supposed to be an indicator of plant morphology was found to decrease in roadside plant species in compare to control. Among the roadside plant species, C. sofera exhibited maximum reduction in SLA. Reduction in SLA specifies poor physiological as well as the biochemical status of the plant. Strong negative correlation has been reported earlier in between dust load and SLA (Raupach et al. 2001, Chaturvedi et al. 2013). Continuous exposure to dust in leaf surface leading to the formation of dense dust layers, which reduce light capturing capacity of plants (Prajapati \& Tripathi 2008a, Pourkhabbaz et al. 2010) and finally hamper plant photosynthetic activity. Light capturing capacity of leaf via lowering photosynthetic rates, clogged stomata and increased foliage temperature are the cause behind dust deposition reported earlier (Anthony 2001). Stomatal index has been proven to be an indicator of environmental stress (Gostin 2009). Decreased rate of photosynthesis and alteration of stomatal conductance are responsible for reduction of the stomatal index as well as dry matter content of leaf (Khan et al. 2015). Reduction of the stomatal index (abaxial and adaxial) of the roadside plant may be due to shading effect of dust layers, which may block the stomata and reduce the photosynthesis rate of roadside plants. The Same impact also reflected on reduced leaf dry matter content. Reduction percentage of the stomatal index and leaf dry matter were found higher in $C$. tora plant compared to other two roadside plant species. It was already evident that leaf of $C$. tora accommodated more dust in first two weeks, hence initial response of reduction of stomatal index and leaf dry matter may be higher than the other two plant species. Leaf thickness was found to increase in all the roadside plants; however, maximum leaf thickness was observed in $C$. sofera than other two plant species. It is also evident that plant under the environmental stress, produces thicker leaves as an adaptive response (Satao et al. 1993, Hope et al. 1999, Gostin 2009) and to cope with the stress of vehicular dust, roadside plants may produce thicker leaves. www.tropicalplantresearch.com 
Roadside plants indicate a reduction in the percentage of nitrogen in compare to control. Actually, dust deposition alters the photosynthesis capacity and hampered the overall growth and development of the plant (Thomson et al. 1984). Therefore, those plants are unable to uptake required nitrogen under such condition. Accumulation of carbon was more resulting higher carbon percentage in plant tissue. It may be a part of plant defence mechanisms because under stress condition plant produces more carbon based secondary metabolites. Finally, present study suggested that alteration of leaf chemistry may be the result of heavy dust load which lowered the nitrogen concentration in plant tissue and greater carbon uptake as a part of the adaptive response.

\section{CONCLUSION}

Present work provides basic information about the variation in dust accumulation of three roadside plant species i.e. Cassia sofera then to $C$. tora and C. alata. Variation of dust loads positively correlated with the alteration of biochemical and epidermal constituents of the leaf. Significant variation in terms of dust deposition with species specific effect observed during the study. In future, to monitor dust fall at roadside areas these representative plant species can be used as an indicator.

\section{ACKNOWLEDGEMENTS}

This work was funded by Department of Science and Technology (DST), Government of India for INSPIRE fellowship and Council of Scientific and Industrial Research (CSIR), Govt. of India under Project No. BSC 111. Authors are also indebted to Director, CSIR-North East Institute of Science and Technology, Jorhat, Assam, India for giving necessary infrastructure and support.

\section{REFERENCES}

Anthony P (2001) Dust from walking tracks: Impacts on rainforest leaves and epiphylls. Cooperative Research Centre for Tropical Rainforest Ecology and Management, Australia.

Arnon DI (1949) Copper enzymes in isolated chloroplasts, polyphenoxidase in Beta vulgaris. Plant Physiology 24: $1-15$.

Beckett KP, Freer-Smith PH \& Taylor G (2000) Particulate pollution capture by urban trees effect of species and wind speed. Global Change Biology 6: 995-1003.

Chaphekar SB, Boralkar DB \& Shetye RP (1980) Plants for air monitoring in industrial area. In: Furtado JI (ed) Tropical Ecology and Development. I.S.T.E. Kuala Lampur, pp. 669-675.

Chaturvedi RK, Prasad S, Rana S, Obaidullah SM, Pandey V \& Singh H (2013) Effect of dust load on the leaf attributes of the tree species growing along the roadside. Environmental Monitoring and Assessment 185(1): 383-391.

Davison AW \& Blakemore J (1976) In: Mansfield TA (ed) Effects of air pollutions on plants. Cambridge University Press, Cambridge, pp. 209.

Farmer AM (1993) The effects of dusts on vegetation; A review. Environmental Pollution 79: 63-75.

Federrer WT (1947) Experimental Design-Theory and Application. Oxford and IBH Publishing Co., London. pp. 114.

Fowler D \& Cape JN \& Unsworth MH (1989) Deposition of atmospheric pollutants on forests. Philosophical Transaction of the Royal Society London, Biological Sciences 324: 247-265.

Gostin IN (2009) Air pollution effects on the leaf structure of some Fabaceae species. Notulae Botanicae Horti Agrobotanici Cluj-Napoca 37: 57-63.

Hope AS, Fleming JB, Stow DA \& Aguado E (1999) Tussock tundra albedos on the north slope of Alaska: Effects of illumination, vegetation composition, and dust deposition. Journal of Applied Meteorology 30: 1200-1206.

Keller J \& Lamprecht R (1995) Road dust as an indicator for air pollution transport and deposition: An application of SPOT imagery. Remote Sensing and Environment 54: 1-12.

Khan ZS, Wolfram S, Yang P, Xiaoning Z, Hussein O, Xiongkui H \& Muller J (2015) Effect of Dust Deposition on Stomatal Conductance and Leaf Temperature of Cotton in Northwest China. Water 7: 116-131.

Meidner H \& Mansfield TA (1968) Physiology of stomata. McGraw-Hill, New York, pp. 140-143.

Manno E, Varrica D \& Dongarra G (2006) Metal distribution in road dust samples collected in an urban area close to a petrochemical plant at Gela, Sicily. Atmospheric Environment 40: 5929-5941.

Nicholson KW, Branson JR, Geiss P \& Cannel RJ (1989) The effects of vehicle activity on particle re suspension. 
Journal of Aerosol Science 20: 1425-1428.

Pandey DD \& Kumar S (1996) Impact of cement dust pollution on biomass, chlorophyll, nutrients and grain characteristics of wheat. Journal of Environmental Ecology 14: 872-875.

Pourkhabbaz A, Rastin N, Olbrich A, Langenfeld-Heyser H \& Polle A (2010) Influence of Environmental Pollution on Leaf Properties of Urban Plane Trees, Platanus orientalis L. Bulletin of Environmental Contamination and Toxicology 85: 251-255.

Prajapati SK \& Tripathi BD (2008b) Seasonal variation of leaf dust accumulation and pigment content in plant species exposed to urban particulates pollution. Journal of Environmental Quality 37: 865-870.

Prajapati SK \& Tripathi BD (2008a) Bio monitoring seasonal variation of urban air Polycyclic Aromatic Hydrocarbons (PAHs) using Ficus benghalensis leaves. Environmental Pollution 151: 543-548.

Prusty BAK, Mishra PC \& Azeez PA (2005) Dust accumulation and leaf pigment content in vegetation near the national highway at Sambalpur, Orissa, India. Ecotoxicology and Environmental Safety 60: 228-235.

Raupach MR, Woods N \& Dorr G (2001) The entrapment of particles by windbreaks. Atmospheric Environment 35: 3373-3383.

Satao RN, Kene HK, Nalamwar RV \& Ulemale RB (1993) Effect of cement dust pollution on growth and yield of cotton. Annual Review of Plant Physiology 7: 73-77.

Thomson JR, Mueller PW, Fluckinger W \& Rutter AJ (1984) The effect of dust on photosynthesis and its significance for roadside plants. Environmental Pollution Series A 34: 171-190.

Vora AB \& Bhatnagar AR (1986) Comparative study of dust fall on the leaves in high pollution and low pollution areas of Ahmedabad. Pollution Research 5: 153-157. 